\title{
Water Chemistry in Oil and Gas Operations: Scales Properties and Composition
}

\author{
Abdullah Taha, Mahmood Amani \\ Texas A \& M University at Qatar, Education City, Qatar \\ Email: mahmood.amani@qatar.tamu.edu
}

How to cite this paper: Taha, A. and Amani, M. (2019) Water Chemistry in Oil and Gas Operations: Scales Properties and Composition. International Journal of Organic Chemistry, 9, 130-141. https://doi.org/10.4236/ijoc.2019.93012

Received: July 9, 2019

Accepted: August 25, 2019

Published: August 28, 2019

Copyright $\odot 2019$ by author(s) and Scientific Research Publishing Inc. This work is licensed under the Creative Commons Attribution International License (CC BY 4.0).

http://creativecommons.org/licenses/by/4.0/

(c) (i) Open Access

\begin{abstract}
Oil and gas operations depend heavily on water in many different aspects. Water is present wherever there is hydrocarbon production. It is produced along with the hydrocarbons and helps in mobilizing them. It is also injected into the reservoirs to aid in mobilizing the hydrocarbons, maintain the pressure and increase the recovery of the development project. With water presence, some serious problems occur such as scaling. Scaling is a well-known problematic precipitation caused mainly due to mixing of two incompatible fluids, changes in temperature and pressure conditions and disturbance to thermodynamics and kinetics of reservoir fluids. They can be found at any point of the operations starting down at the formation up to the surface tanks. Scales are directly responsible for compromising the economics and safety of development projects. This review paper is going to include a recap of the importance of water in the oil and gas industry, then review the different types of scales as well as their properties including carbonate and sulfate scales. After that, famous scales from each type is going to be reviewed as well as their properties and precipitation conditions such as Calcium Carbonate $\mathrm{CaCO}_{3}$, Calcium Sulfate $\mathrm{CaSO}_{4}$, Barium Sulfate $\mathrm{BaSO}_{4}$ and Strontium Sulfate $\mathrm{SrSO}_{4}$. Moreover, common practices and precautions steps in the industry are going to be reviewed as well. Finally, the paper presents the common practices used by the operators for scale removal.
\end{abstract}

\section{Keywords}

Scale, Calcium, Sulfate, Acid Soluble, Acid Insoluble, Mill

\section{Introduction}

Water in the oil and gas industry is considered as one of the most important drives for hydrocarbons production. Water aids in managing the reservoir, mobilizing the hydrocarbons and displacing them within the homogenous rocks 
[1]. This kind of water production is known as necessary or good water production. Typically, this kind of water is linked with hydrocarbon production in the late stages of water-flooding operations and active aquifers. Another type of necessary water production is the water produced at a low Water Oil Ratio (WOR). That type of water production maintains the profitably of production operations [2]. The reduction of necessary water production directly results in production losses and lower profitability in the production wells [3]. The other type of water production in the oil and gas industry is the un-wanted and excessive water production, which is responsible directly for decreasing the profitability of the development projects by lowering the productivity of production wells [4]. The production of this type of water is a famous issue and present in many fields worldwide. Operators can face this issue in older wells and newly developed wells too [2]. Several complications come along with this type of production such as lowering the performance of the production wells. Excessive water presences in the wellbore surge the production and increase the weight of the fluid column which needs to be lifted. As a result, lifting requirements increase and operating cost increases too. In many cases, that leads to shutting in those wells [5]. For example, the amount of gas used in gas lifted well to lift the fluid from the wellbore to the surface is higher with the heavier fluid caused by the un-wanted water than without it. Another problem associated with unwanted water production is losing oil production due to poor sweep efficiency within the matrix rocks. Un-swept oil pockets areas are formed due to bad conformance jobs in water-flooding operations. Normally, water injection well is injecting to displace oil within the reservoir toward the production wells and maintain the reservoir pressure of the reservoir. In some case, however, the production well happens to be connected directly to the water injection well through an open fracture or high permeability layer. In this case, un-wanted water production is present since the path of least resistance for the injected water is going to be the open fractures or high permeability layers, not the matrix rocks. In this bad conformance case, oil is left in the matrix rocks without meeting the required sweeping efficiency. Another issue coming along with production of excessive water is the separation, treatment and disposal cost. \$ 1 Billion is the annual cost of water disposal only in Alberta [6]. Water shut-off operations are necessary to reduce that kind of expenses and increase the profitability of the development projects. Differentiating between the necessary and unwanted water production is important to maintain the productivity of the well. It can be identified by reviewing the offset wells water cut behavior. It is a bad water production if the offset wells are producing with much lower water cut [7]. Unwanted water production can be also avoided from the designing phase by understanding the formation characterizations and the unique challenges of a certain field [8]. Another famous problem caused usually by the water production, which is the subject of this review paper, is the enhancement of the scale presence in the oil and gas fields facilities. It is usually formed due to injecting an incompatible flu- 
id in the reservoir. It can precipitate from the formation rocks up to separation tanks at the surface [9]. Scale precipitation is directly responsible for lowering the profitability of the production wells. Scales when formed in the wellbore, surface pipes or the separation tanks can affect the productivity of the oil since it reduces the diameters of the pipes and creates, with time, an additional choke to the system. In addition, it can cause many safety issues and it can be radioactive in some cases [10].

\section{Types of Water in Petroleum Industry}

As mentioned previously, water is an important drive energy source that supports mobilizing the hydrocarbons from the formation rocks to the wellbore. In hydrocarbon industry, there are two main kinds of water, Reservoir water and Injection water. Reservoir water is the separated water from the liquid produced along with oil during the production operations. It varies in properties based on the source of the water, precipitations, contaminants, dissolved solids and $\mathrm{pH}$. Those different properties can be identified along with the production operations by collecting samples, performing laboratory tests and simulating the reservoir drive mechanism and boundaries. It is important to identify the properties to be ready for the problems that can come along with water production such as scaling precipitation. At early stages of production operations, water is produced in small quantities in form of emulsion. Water production continues to increase with time to a point that the well is uneconomical anymore. It can be due to water breakthrough, communication with aquifers or water conning as showing in (Figure 1).

Reservoir water is known as Brine because of the dissolved solids in different concentrations and ions distribution such as sodium chloride $(\mathrm{NaCl})$. The most common dissolved solids in brine are Sodium (Na), Calcium (Ca), Magnesium

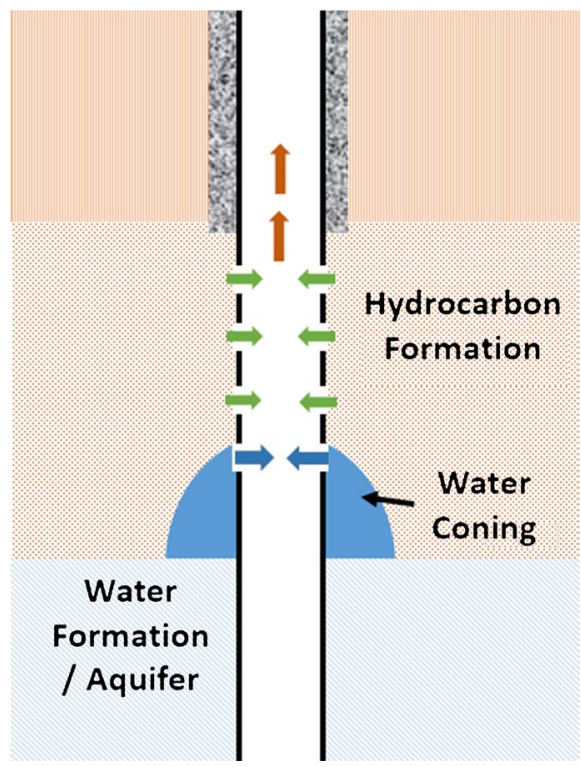

Figure 1. Water coming in the wellbore. 
$(\mathrm{Mg})$, Chlorine $(\mathrm{Cl})$, Sulfate $\left(\mathrm{SO}_{4}\right)$. The less common dissolved solids are Barium (Ba), Lithium ( $\mathrm{Li})$, Iron $(\mathrm{Fe})$, Strontium $(\mathrm{Sr})$, Bicarbonate $\left(\mathrm{HCO}_{3}\right)$, Carbonate $\left(\mathrm{CO}_{3}\right)$, Nitrate $\left(\mathrm{NO}_{3}\right)$, Bromine $(\mathrm{Br})$, Iodine (I), Borate $\left(\mathrm{BO}_{3}\right)$ and Sulfur (S). They are usually dissolved as cations and anions shown in Table 1 [11].

With more production, reservoir pressure decreases and this is the point water injection is needed to enhance the recovery of the development project. Water flooding operations aim to maintain the pressure in the reservoir to drive the hydrocarbons toward the production wells. Water used in the water flooding operation comes from different sources such as Surface, Shallow, Deep, Sea or Produced Water. Surface water comes from rivers and lakes and not recommended due to high solids and oxygen content. Shallow and deep water are reservoir waters that are accumulated underground. They are oxygen free but deep reservoir water are higher in salinity. Seawater is the most type used in the offshore development projects and water from deeper sources are higher in quality. Solids filtering and oxygen scavenging is needed prior injection for seawater. Produced water is the separated water from production operations and considered as the lowest in quality due to the treatments needed before reinjecting it into the reservoir. Regardless of the injection source, assessment has to be done to insure compatibility of the injected water with the reservoir. Laboratory test has to be done to determine the quality of the water and specially scaling probabilities. Water studies are important to install the right completions as well as chemical inhibitors to prevent scaling. Incompatible water are the main reason behind scale precipitation. Dissolved solids react if the injected water is not compatible with the formation water [12].

\section{Scales in Petroleum Industry}

Scaling is a well-known precipitation caused by water in the petroleum industry. Scales are crystals that usually form in the pipelines and wellbores near surface, downhole and at surface equipment with fluctuations of thermodynamics, kinetics and changes in pressure and temperature values. They are directly responsible for

Table 1. Dissolved cations and anions in brine.

\begin{tabular}{cc}
\hline Cations & Anions \\
\hline Sodium $\left(\mathrm{Na}^{+}\right)$ & Chlorine $\left(\mathrm{Cl}^{-}\right)$ \\
Calcium $\left(\mathrm{Ca}^{2+}\right)$ & Sulfate $\left(\mathrm{SO}_{4}^{2-}\right)$ \\
Magnesium $\left(\mathrm{Mg}^{2+}\right)$ & Bicarbonate $\left(\mathrm{HCO}_{3}^{-}\right)$ \\
Potassium $\left(\mathrm{K}^{+}\right)$ & Carbonate $\left(\mathrm{CO}_{3}^{2-}\right)$ \\
Barium $\left(\mathrm{Ba}^{2+}\right)$ & Nitrate $\left(\mathrm{NO}_{3}^{-}\right)$ \\
Lithium $\left(\mathrm{Li}^{+}\right)$ & Bromine $\left(\mathrm{Br}^{-}\right)$ \\
Iron $\left(\mathrm{Fe}^{2+}\right)$ & Iodine $\left(\mathrm{I}^{-}\right)$ \\
& Borate $\left(\mathrm{BO}_{3}^{3-}\right)$ \\
Strontium $\left(\mathrm{Sr}^{2+}\right)$ & Sulfur $\left(\mathrm{S}^{2-}\right)$
\end{tabular}


causing reduction in production due to the decrease of the internal production tubing and pipelines diameters and in many cases can cause a total plug. Hence, the profitability of a development project can be impacted severely by scale presence. Mixing of incompatible waters is also one of the main reasons behind scale forming, which is a common problem after water breakthrough in hydrocarbon fields. As mentioned previously, oil and gas industry depends heavily on water in many different aspects. Wherever there is oil or gas production, water is present. However, the scaling increases with more water production. The presence of water is necessary for the scales to be formed. Without the water, there is no scaling issue at all. Nevertheless, water is always present in the oil and gas industry.

Scales can form at any point and in any place of the operations starting from the reservoir, wellbore, production pipes, surface vales and separators. Therefore, they can cause serious issues at any point of the operation such as blocking the near wellbore, downhole completion/perforations, surface chokes, valves and separators. At near wellbore, the scale precipitation can occur creating an extra barrier/choke, which restricts hydrocarbon flow to the wellbore. This extra barrier or reduction in the internal diameter can also be formed around the perforations holes, screens and inside the production tubing (Figure 2). In some sever cases can reach up to $100 \%$ blockage. Scales are also responsible of damaging the downhole equipment such as ESP (Electric submersible pumps), chokes and valves (Figure 3 ). When scales precipitate inside chokes and vales, that can results in losing the ability to control them (unworkable) or even make them stuck in one position. That adds a high level of risk to the entire operation. All of those issues lead to expensive workovers, mechanical and chemical solutions. Moreover, huge losses in production occur as well. Therefore, the profitability of a development project could be harmed severely due to scales.

The scales are formed due to several reasons. First cause of scaling formation

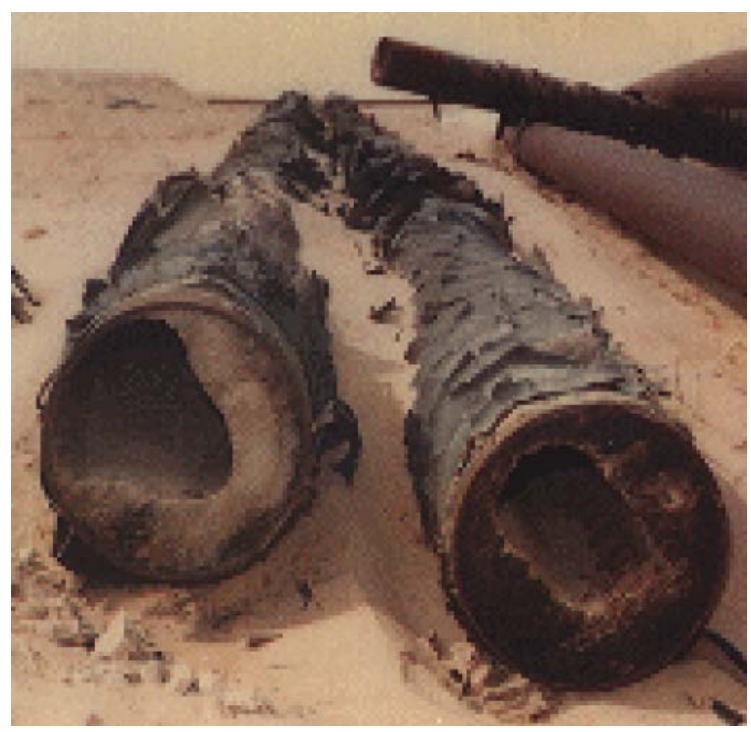

Figure 2. Calcium carbonate $\mathrm{CaCO}_{3}$ scale precipitation inside production pipes [13]. 


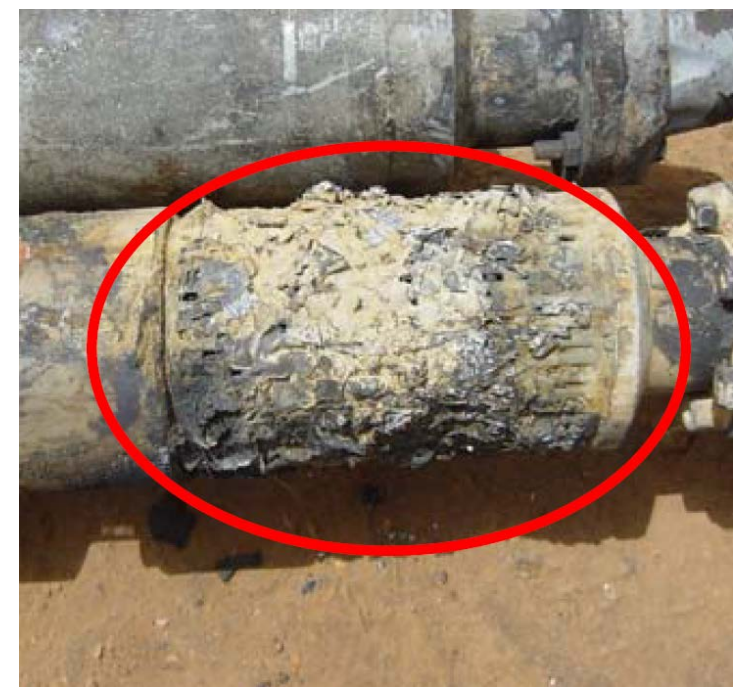

Figure 3. Calcium carbonate $\mathrm{CaCO}_{3}$ scale blocking pump intake [14].

is the change of temperature and pressure. That can stimulate scales precipitation. This reason mainly responsible for creating carbonate scales. Second cause, which is the main reason, is mixing injection and formation waters that produces the incompatible waters into the reservoirs, which is usually responsible for creating sulfate scales. For example, injection water that contains high content of sulfate when mixed with formation water that contains barium, strontium or calcium results in formation of different types of scales like Barium Sulfate Ba$\mathrm{SO}_{4}$, Strontium Sulfate $\mathrm{SrSO}_{4}$ and Anhydrite $\mathrm{CaSO}_{4}$. Chemical reactions take place within the formation rocks when making contact with the incompatible fluid. Then the reaction allows the fluid to transport the dissolved ionic which at later stage precipitate with specific ranges of temperatures and pressures. Other elements also control the scaling process such as $\mathrm{pH}$ and salinity.

Scales are mainly categorized into two types; Sulfates scales or acid insoluble and Carbonates scales or Acid soluble.

\subsection{Acid Soluble Scales}

Carbonates scales are the most common scales in the oil and gas industry. They are known also as acid soluble scales since they are soluble in acid and can react easily with it. Soluble scales, when compared with insoluble scales, are relatively easy to cure. These types of scales are usually formed due to change of temperature and pressure values, which stimulate scales precipitation. The most common soluble scale is Calcium Carbonate $\mathrm{CaCO}_{3}[15]$.

\section{Calcium Carbonate $\mathrm{CaCO}_{3}$}

As mentioned previously, Calcium Carbonate $\mathrm{CaCO}_{3}$ is the most famous type of scales worldwide in oil and gas industry (Figure 1 and Figure 2). This well-known type is formed due to changes in pressure and temperature. Calcium Carbonate precipitation and formation tends to increase also due to the dynamics of mixing different fluids in the reservoir with changes in conditions. In fact, 
water, oil and gas can all increase the tendency of calcium carbonate to form. Their compositions along with pressure and temperature are important to be identified in order to expect the formation of calcium carbonate scale. Other properties are also significant to be recognized such as bubble point pressure, $\mathrm{CO}_{2}$ distribution in the fluid, water oil ratio and gas oil ratio. Usually, calcium carbonate scale is formed in the upper parts of completions [16]. The most common way of calcium carbonate formation is due to one of the cations dissolved in brine is Calcium $\left(\mathrm{Ca}^{2+}\right)$ when mixed with $\mathrm{CO}_{2}$ under certain conditions of pressure, temperature and volumes. Initially, fluids inside the reservoir are in thermodynamic equilibrium. Once the production operation starts, changes are introduced to the system. That disturbs the equilibrium of the fluids. Those changes are mainly the pressure and temperature, which encourage occurrence of chemical reactions [15]. Squeezing inhibitors into the wellbore has a good impact in preventing calcium carbonate precipitation such as SI-A and SI-E inhibitors. When formed, calcium carbonate can be removed by pumping acids or by using milling tools [16].

\subsection{Acid Insoluble Scales}

Sulfate scales are the less common scales in the oil and gas industry yet very challenging and problematic when precipitate if compared with carbonates scales. They are known also as acid insoluble scales since they are insoluble in acid and do not react easily with it. Insoluble scales, when compared with soluble scales, are relatively hard to cure. They add a significant risk to the whole operations. As mentioned previously, mixing injection and formation waters introduces incompatible waters into the reservoirs. That is usually responsible of creating sulfate scales. For example, injection water that contains high content of sulfate when mixed with formation water that contains barium, strontium or calcium results in formation of different types of scales like Barium Sulfate Ba$\mathrm{SO}_{4}$, Strontium Sulfate $\mathrm{SrSO}_{4}$ and Anhydrite $\mathrm{CaSO}_{4}$. Chemical reactions take place within the formation rocks when making contact with the incompatible fluid. Then the reaction allows the fluid to transport the dissolved ionic which at later stage precipitate with specific ranges of temperatures and pressures. Other elements also control the scaling process such as $\mathrm{pH}$ and salinity.

The following are the most common types of insoluble scales.

\subsubsection{Calcium Sulfate $\mathrm{CaSO}_{4}$}

Calcium Sulfate $\mathrm{CaSO}_{4}$ is one type of insoluble scales. This type of scale, like other sulfate scales, adds a lot of risk to the operation. It can be found in many points of the operations in oil and gas industries and other water treatment processes too. There are two types of calcium sulfate. The first one is calcium sulfate dehydrate, which is known by the term (gypsum). This type usually precipitates at the surface facilities that have relativity low temperature. The second type of calcium sulfate is Anhydrite $\mathrm{CaSO}_{4}$. This type, on contrary of gypsum, usually precipitates with higher pressure and temperature values [17]. Calcium 
sulfate is formed from Calcium $\left(\mathrm{Ca}^{2+}\right)$ cation and Sulfate $\left(\mathrm{SO}_{4}^{2-}\right)$ anions. The primary reason of calcium sulfate scaling is the mixture of two incompatible fluids such as formation water and injection water. Usually, seawater is used in water flooding operations especially in offshore operations and it contains high amount of Sulfate $\left(\mathrm{SO}_{4}^{2-}\right)$ anions. On the other side, some formation water has high quantity of Calcium $\left(\mathrm{Ca}^{2+}\right)$ cation. When those two incompatible fluids are mixed, with the right temperature and pressure, calcium sulfate scale precipitate [18].

Like other types of scales, initial sampling and studies has to be done to detect the possibility of calcium sulfate precipitation in the operation. Calcium sulfate scale, when expected to form inside the pipes of the facilities, can be prevented using chemical inhibitors such as HDTMP inhibitor (Hexamethylenediamine tetra/methylene phosphonic acid). Moreover, operators have to keep a close attention of other surrounding liquid and chemical used during the operations since it can encourage calcium sulfate precipitation. For example, more scale inhibitors is recommended to be used with the existence of other fluids such as methanol [17].

\subsubsection{Barium Sulfate $\mathrm{BaSO}_{4}$}

Barium Sulfate $\mathrm{BaSO}_{4}$ forms usually in the carbonate reservoirs with barium content and water-flooding operations that use seawater. Barium sulfate is formed from Barium $\left(\mathrm{Ba}^{2+}\right)$ cation and Sulfate $\left(\mathrm{SO}_{4}^{2-}\right)$ anions. The primary reason of barium sulfate scaling is the mixture of two incompatible fluids such as formation water and injection water. Usually, seawater is used in water flooding operations especially in offshore operations and it contains high amount of Sulfate $\left(\mathrm{SO}_{4}^{2-}\right)$ anions [9]. On the other side, some formation water has high quantity of Barium $\left(\mathrm{Ba}^{2+}\right)$ cation. When those two incompatible fluids are mixed, with the right temperature and pressure, barium sulfate scale precipitate [18]. It is the one of the most challenging scales in oil and gas industries especially for offshore fields. Usually, costly workovers are needed to solve the barium sulfate problems. Therefore, it can be a nightmare when precipitate for the operators. Barium sulfate formation can be predicted using thermodynamic and kinetics relations [19]. Another simple way to predict the barium sulfate scaling tendency is by sampling the produced water and analyze cations and anions content, especially Sulfate $\left(\mathrm{SO}_{4}^{2-}\right)$ and Barium $\left(\mathrm{Ba}^{2+}\right)$. To make it more accurate, all properties has to be considered such as thermodynamics conditions, pressure and temperature. Barium sulfate is very hard to cure if not identified at early stages. Usually, motored mills are used to mill the scale with very low successful rates [16].

\subsubsection{Strontium Sulfate $\mathrm{SrSO}_{4}$}

$\mathrm{SrSO}_{4}$ is another serious type of sulfate scales, which adds a lot of risk to the operation (Figure 4). It is considered challenging like Barium Sulfate. They both usually require workover and rig interventions to remove them. Usually, Strontium sulfate scale is formed in the lower parts of completions [16]. Strontium 


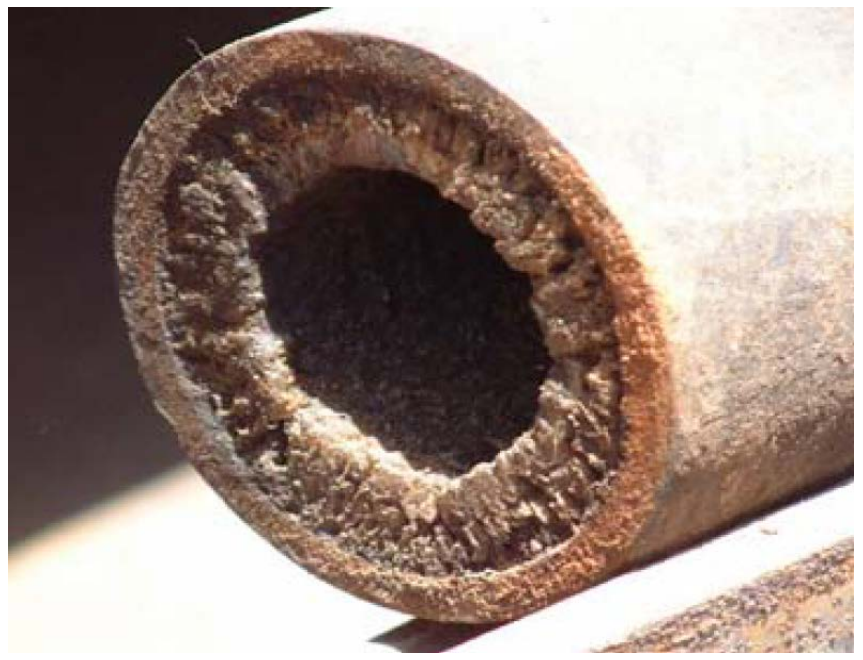

Figure 4. Strontium sulfate $\mathrm{SrSO}_{4}[16]$.

sulfate is formed from Strontium $\left(\mathrm{Sr}^{2+}\right)$ cation and Sulfate $\left(\mathrm{SO}_{4}^{2-}\right)$ anions. The main cause of strontium sulfate scaling is the combination of two incompatible fluids like formation water and injection water. Typically, seawater is used in water flooding operations especially in offshore operations and it contains high amount of Sulfate $\left(\mathrm{SO}_{4}^{2-}\right)$ anions. On the other side, some formation water has high quantity of Strontium $\left(\mathrm{Sr}^{2+}\right)$. When those two incompatible fluids are mixed, with the right temperature and pressure, strontium sulfate scale precipitate [18]. Like barium sulfate, strontium sulfate is very hard to cure if not identified at early stages. Usually, motored mills are used to mill the scale with very low successful rates [16].

\section{Recommended Practices}

In this section of the paper, a brief summary of common practices used by the operators to prevent and solve scale precipitation problem is presented. However, before presenting the methods, operators must study and understand the scaling formation in their fields with taking into consideration all the properties and surrounding effects such as fluids used in the operations and other expected types of scales. Operators also must be aware of their reservoir formation water properties as well as the injection water that is used in the water-flooding operations. For example, if the water used in the injection operation has high content of sulfate ions and it is going to be used in a reservoir with high barium/ strontium or calcium ion content, it is recommended to treat the injection water by removing sulfate ions prior using it [9]. Operators also have to sample the produced water regularly to keep a close attention for any chlorides content change, which usually indicates water breakthrough. Hence, beginning of mixing of incompatible fluids. It is important to study all the aspect and properties because some scales when precipitate together are more problematic and challenging than if they are precipitate separately. For example, calcium sulfate and barium sulfate scales are much harsher when precipitate together and more challenging 
than single precipitation. In this particular case, chemical inhibitors like SI-A and SI-E have high effectiveness in dealing with multiple scale precipitation [18]. One of the most famous and effective ways of preventing scale precipitation is the usage of chemical inhibitors. Chemical inhibitors are used to prevent scale buildup through downhole chemical injection into the wellbore. The amount of the inhibitors required depends on the properties of each field such as concentration of minerals dissolved in the produced water, temperature, $\mathrm{pH}$ and pressure [10]. Inhibitors are injected into the wellbore usually through control lines at certain depths. Operators can also use simulation software to predict the scale precipitation as well as the effects of the suggested injection water to be used in the water-flooding operations [9]. Operators can also develop scale risk matrix (SRM) to categories risk levels associated with each scale for wells in the field [16]. For mechanical solutions, when there is a chloride content change, wireline gauge cutter is recommended to be used. Gauge cutter is used to run inside the wells to indicate any scale build up and to act accordingly. Wireline is used to remove the scale build-up by running scratchers and gauge cutters to scratch the internal wells of production pipes. Nozzles and jets are also used to clean the internal walls. Mills are used in extreme cases as well [16].

\section{Conclusion}

In conclusion, scales are common in oil and gas industry and can form at any points of the process starting from the downhole to the separator tanks. Scale presence effects the profitability of development projects and compromises the safety of the operations as well. Several aspects control scale formation such as pressure, temperature and mixing incompatible fluids. It is essential for the operators to understand the properties of reservoir liquids and injected water used in the water-flooding operation very well to help them prevent or predict scale formation. Although early prediction is helpful, prevention is better than cure. Usage of inhibitors in wells that are drilled in formations known with scale problems or conditions that encourage scale precipitation is essential to save the cost of interventions needed in the future to solve the scaling issues and to optimize the production as well. In addition, sampling the produced water regularly and testing the chloride content are helpful to indicate water breakthrough and mixing of incompatible fluids inside the reservoir.

\section{Conflicts of Interest}

The authors declare no conflicts of interest regarding the publication of this paper.

\section{References}

[1] Taha, A. and Amani, M. (2019) Importance of Water Chemistry in Oil and Gas Operations: Properties and Composition. International Journal of Organic Chemistry, 9, 23-36. https://doi.org/10.4236/ijoc.2019.91003

[2] Joseph, A. and Ajienka, J.A. (2010) A Review of Water Shutoff Treatment Strategies 
in Oil Fields. The Annual SPE International Conference and Exhibition, Tinapa-Calaber, Nigeria, 31 July-7 August 2010, SPE 136969. https://doi.org/10.2118/136969-MS

[3] Sydansk, D. and Romero-Zeron, L. (2011) Reservoir Conformance Improvement. Society of Petroleum Engineers, San Antonio, Texas.

[4] Seright, R.S., Lane, R.H. and Sydansk, R.D. (2003) A Strategy for Attacking Excess Water Production. SPE Production \& Facilities, 18, 158-169. https://doi.org/10.2118/84966-PA

[5] Ahmad, N., Al-Shabibi, H. and Malik, S. (2012) Comprehensive Diagnostic and Water Shut-off in Open and Cased Hole Carbonate Horizontal Wells. The Abu Dhabi International Petroleum Exhibition and Conference, Abu Dhabi, UAE, 11-12 November 2012, SPE 162287. https://doi.org/10.2118/162287-MS

[6] Thomas, F.B., Bennion, D.B., Anderson, G.E., Meldrum, B.T. and Heaven, W.J. (2000) Water Shut-off Treatments-Reduce Water and Accelerate Oil Production. Journal of Canadian Petroleum Technology, 39, 25-29. https://doi.org/10.2118/00-04-TN

[7] Permana, D., Ferdian, G., Aji, M. and Siswati, E. (2015) Extracting Lessons Learned of 35 Water Shut-off Jobs in Mature Fields to Improve Success Ration of Water Shut-off Job. The SPE/IATMI Asia Pacific Oil \& Gas Conference and Exhibition, Bali, Indonesia, 20-22 October 2015, SPE-176191-MS. https://doi.org/10.2118/176191-MS

[8] McIntyre, F.J., Grenon, J.P. and See, D.L. (1999) Horizontal Well Gas/Water Shutoff-Field Results. Journal of Canadian Petroleum Technology, 38, 23-27. https://doi.org/10.2118/99-10-01

[9] Li, Y., Crane, S. and Coleman, J. (1995) A Novel Approach to Predict the Co-Precipitation of $\mathrm{BaSO}_{4}$ and $\mathrm{SrSO}_{4}$. The SPE Production Operations Symposium, Oklahoma, 2-4 April 1995, SPE-29489. https://doi.org/10.2118/29489-MS

[10] Al-Thuwaini, J. and Burr, B. (1997) Encapsulated Scale Inhibitor Treatment. The Middle East Oil Show, Manama, Bahrain, 15-18 March 1997, SPE-37790. https://doi.org/10.2118/37790-MS

[11] McCain, W. (1990). The Properties of Petroleum Fluids. 2nd Edition, PennWellBooks, Tulsa, Oklahoma.

[12] Endean, H. and Shelton, R. (1991) Water Initiated Problems in Production Operations. Champion Technologies, Inc., Houston, TX.

[13] Raju, K.U., Baruah, K., AL-Otaibi, N.M. and Al-Shammari, F.G. (2011) Proactive Scale Mitigation Strategies for Simple to Complex Multilateral Producers in a Saudi Arabian Carbonate Field. Middle East Oil and Gas Show and Conference, Manama, Bahrain, 25-28 September 2011, SPE-141374. https://doi.org/10.2118/141374-MS

[14] Nasr-El-Din, H.A., Al-Gamber, S.D. and Saiari, H.A. (2006) Field Application of Emulsified Scale Inhibitor Treatment to Mitigate Calcium Carbonate Scale in Horizontal Wells. International Oilfield Scale Symposium, Aberdeen, United Kingdom, 30 May-1 June 2006, SPE-100456. https://doi.org/10.2118/100456-MS

[15] Vetter, O. and Farone, W. (1987) Calcium Carbonate Scale in Oilfield Operations. Annual Technical Conference and Exhibition of the Society of Petroleum Engineers, Dallas, TX, 27-30 September 1987, SPE-16908-MS. https://doi.org/10.2118/16908-MS

[16] Al-Ashhab, J., Al-Matar, H. and Mokhtar, S. (2006) Techniques Used to Monitor and Remove Strontium Sulfate Scale in UZ Producing Wells. Abu Dhabi Interna- 
tional Petroleum Exhibition and Conference, Abu Dhabi, UAE, 5-8 November 2006, SPE-101401. https://doi.org/10.2118/101401-MS

[17] Kan, A.T., Fu, G., Shen, D., Fan, C. and Tomson, M.B. (2009) Quantitative Evaluation of Calcium Sulfate Precipitation Kinetics in the Presence and Absence of Scale Inhibitors. International Symposium on Oilfield Chemistry, Society of Petroleum Engineers, San Antonio, TX, 20-22 April 2009, SPE-121563. https://doi.org/10.2118/121563-MS

[18] Liu, X., Chen, T., Chen, P., et al. (2012) Understanding the Co-Deposition of Calcium Sulphate and Barium Sulphate and Developing Environmental Acceptable Scale Inhibitors Applied in HTHP Wells. International Conference and Exhibition on Oilfield Scale, Aberdeen, UK, 30-31 May 2012, SPE-156013-MS. https://doi.org/10.2118/156013-MS

[19] Vetter, O. (1975) How Barium Sulfate Is Formed: An Interpretation. Journal of Petroleum Technology, 27, 1515-1524. https://doi.org/10.2118/4217-PA 